\title{
What is the role of lipid membrane-embedded quinones in ATP-synthesis? Chemiosmotic Q-cycle versus murburn reaction perspective
}

\author{
Kelath Murali Manoj ${ }^{1}$, Daniel Andrew Gideon ${ }^{1}$, Abhinav Parashar ${ }^{2} *$
}

*Corresponding author, ${ }^{1}$ Satyamjayatu: The Science \& Ethics Foundation, Kulappully, Shoranur-2 (PO), Palakkad District, Kerala State, India-679122.

Email: satyamjayatu@yahoo.com

*Corresponding author, ${ }^{2}$ Department of Biotechnology, Vignan's Foundation for Science, Technology \& Research, Vadlamudi, Guntur, India-522213.

\begin{abstract}
Quinones are found in the lipid-membranes of prokaryotes like E. coli and cyanobacteria, and are also abundant in eukaryotic mitochondria and chloroplasts. They are intricately involved in the reaction mechanism of redox phosphorylations. In the Mitchellian chemiosmotic school of thought, membrane-lodged quinones are perceived as highly mobile conveyors of two-electron equivalents from the first leg of Electron Transport Chain (ETC) to the 'second pit-stop' of Cytochrome $b c_{1}$ or $b_{6} f$ complex (CBC), where they undergo a regenerative 'Q-cycle'. In Manoj's murburn mechanism, the membrane-lodged quinones are perceived as one- or two- electron donors/acceptors, enabling charge separation and the CBC resets a one-electron paradigm via 'turbo logic'. Herein, we compare various purviews of the two mechanistic schools with respect to: constraints in mobility, protons' availability, binding of quinones with proteins, structural features of the protein complexes, energetics of reaction, overall reaction logic, etc. From various perspectives, it is concluded that the chemiosmotic Qcycle is an untenable hypothesis. We project the murburn proposal as one rooted in thermodynamics/kinetics and which provides tangible structure-function correlations for the roles of quinones, lipid membrane and associated proteins.
\end{abstract}

Keywords: murburn concept; chemiosmosis; cytochrome $b c_{1}$ or $b_{6} f$; ubiquinone; plastoquinone; Q-cycle; electron carrier; electron transport chain; proton pumps; 


\section{Introduction}

Ubiquinone (CoQ) and plastoquinone (PQ) / phylloquinone $(\mathrm{K})$ are examples of lipid-membrane bound biological quinones found in mitochondrial and chloroplastid/cyanobacterial membranes that are involved in energy metabolism. The 'Chemiosmotically driven Rotary ATP Synthesis' (CRAS) paradigm for energy metabolism was mooted by Mitchell-Boyer, which was developed on Keilin's concept of Electron Transport Chain (ETC) (Boyer, 1998; Mitchell, 1979). The ETCCRAS mechanism proposed that quinones ferry two-electron equivalents from the "primary pitstop' of Complex I / II or Photosystem II to the 'secondary pit-stop' of Cyt. $b c_{1}$ (Complex III) or Cyt. $b_{6} f$ complexes (which we shall address together as $\mathrm{CBC}$ ), in the routines of mitochondrial oxidative phosphorylation (mOxPhos) and chloroplastid photophosphorylation (cPhotoPhos), respectively. An alternative explanation based in murburn concept was recently proposed for mOxPhos and cPhotoPhos (Manoj, 2017; Gideon et al., 2019; Manoj et al., 2018 a, b, c, d; Manoj et al., 2019 a, b, c, d; Manoj et al., 2020 a, b, c, d, e, f; Manoj and Mannekathodi, 2020; Manoj and Soman, 2020). Within this context, we provide a critical analysis and comparison of the ETC-CRAS and murburn mechanisms for membrane-bound Quinones' and CBC's (Q-CBC) role in energy metabolism, within the organelles of mitochondria and chloroplasts.

\section{Methodology}

The CRAS explanation for energy metabolism was forged in the 1970s, after Mitchell got the Nobel recognition and Boyer proposed the Complex V-aided rotary ATP synthesis proposal that could go along with the 'in vogue idea'. However, several key architectural/physiological facets/facts of mitochondria/chloroplasts and structural features of the membrane proteins were revealed only subsequently, and some of the efforts in this regard are still ongoing. In the light of the simple fact that the vast majority of life forms evolved around oxygen, Manoj deduced that oxygen must have a greater physiological role than what is attributed to it by the ETC-CRAS hypothesis. Therefore, rather than trying to 'rationalize' incompatible aspects of the currently available information to suit the 'acclaimed idea', we would make a critical dissection of the same, building the phenomenological paradigm ab initio from the most elementary and known facts. For, the advancement of science has historically relied on such a process. Next, we shall 
prioritize on the laws of physics, as they are more important than 'biological aesthetics/consensus'. While the latter is a subjective and alterable concept, the former ideas are objective and immutable. Finally, we shall only consider large magnitude of differences in quantitative yardsticks or significant qualitative observational incompatibilities to decide on the viability of hypotheses on Q-CBC.

\section{Results and Discussion}

Lack of consensus among CRAS-advocates on the details of QCBC attributes: At the outset, we must say that even after half a century's pursuits and thousands of manuscripts on the subject, textbooks have continued to portray a very 'confused' picture on the roles of QSPS. A brief study of salient literature shows that 'acclaimed researchers' continue to portray quite distinct mechanisms and stoichiometries for the roles of QCBC. As a result of this, younger generation is given very contrasting set of ideas via textbooks. For example: (i) Voet shows that CoQ pumps protons into inter-membrane space (IMS) whereas in Lehninger, it is Cyt. $b c_{1}$ that does this work. (ii) A similar picture is noted for the chloroplast system too wherein Ahern shows PQ pumping protons into thylakoid lumen whereas Lodish's text shows Cyt. $b_{6} f$ discharging this function. (iii) In recent times, two Asian groups' reviews showed 4 protons per 2e whereas two European groups' reviews showed 2 protons per $2 \mathrm{e}$, for the same protein- Complex III. The confusion is not just between groups, even reputed individual researchers like Wikstrom showed both 2 and 4 protons pumped per 2e by Complex III, and such suppositions are published in very highly reputed journals. (iv) The three examples above need to be placed in the context that Nalecz had specifically pointed out with both monomers and dimers that of Complex III that there is no explicit evidence that it functions as a proton pump (Nałęcz, 1986). The multiple versions of the CRAS proposal makes it a 'shape/color-shifting chameleon' to critique and the exercise is akin to aiming at a non-precise bull's eye. This has resulted because the hypothesis is inaccurate and/or the experimental outcomes cannot be correlated to the assumptions. [These statements are supported by the fact that the original proposer of the proton pump concept, Peter Mitchell, did not accept Complex IV to be a proton pump. It was that when over time the advocates realized that ATP synthesis by CRAS scheme would otherwise be unviable, the advocates started with 2 protons per $2 \mathrm{e}$ and seem to have reached a consensus that Complex IV 
pumps 4 protons per 2e! Visual evidence to substantiate the affirmations made above is presented along with the details of literature in Supplementary Information, Item I.] In spite of the above arguments, in the sections that follow, we shall consider select generic and specific aspects of the 'chemiosmotic ideas' found in reputed textbooks, reviews and original research publications.

Structure, distribution and mobility of quinones: Biologically found membrane-bound quinones are diketone non-aromatic derivatives of mono- or bi- nucleated aromatic molecules substituted with diverse hydrophobic moieties/chains, particularly isoprenoids (Figure 1). The most common lipids in mitochondria and thylakoids are phosphatidylethanolamine (Osman et al., 2011) and monogalactosyldiacylglycerol (Schaller et al., 2010), respectively. These lipids, with the most common palmitic $\left(\mathrm{C}_{16}\right)$ /stearic $\left(\mathrm{C}_{18}\right)$ chain substitutions have the lipid-phase linear extension of $\sim 2.5 \mathrm{~nm}$. In comparison, the most commonly found quinones of mitochondria and chloroplast are $\mathrm{CoQ}_{10}$ (linear $\mathrm{C}_{40}$ for the isoprenoid chain) and $\mathrm{PQ}_{9}$, (linear $\mathrm{C}_{36}$ for the isoprenoid chain) respectively and this relates to a linear dimension of $\sim 5 \mathrm{~nm}$. While the inner mitochondrial lipid bilayer (including the peripheral polar headgroups and minimal hydration shell) thickness is $\sim 7$ nm (Perkins et al., 1997), the core hydrophobic sandwiched part would be maximally $~ 3.0$ to 4.5 $\mathrm{nm}$ thick, connoting to a length of $\sim 35 \mathrm{C}$-C bonds. Therefore, the bulky hydrophobic substituent group (which also has several methyl substitutions at the $s p^{2}$ carbon of each isoprenoid unit) of the quinones would make its translational diffusion through the viscous hydrophobic region difficult, when compared to the relatively facile motility of the unsubstituted/shorter fatty acyl chains. In this regard, the ETC-CRAS scheme cannot explain why the membranes should harbor quinones with varying lengths of isoprenoid chains (as exemplified by $\operatorname{CoQ}(6-10)$ and $P Q_{(3-9)}$ ), and why the longer chain length isoprenoid species should be predominant. If CoQ was a chargerelayer for the crucial ETC, it would make more sense to have the shorter length quinones, which would serve as faster connection between the pit-stops of ETC. The complete and partial reduction of quinone leads to the formation of ubiquinol and semiquinone (which are more polar; with lower $\log \mathrm{P}$ and higher total polar surface areas) and have $\mathrm{pK}_{\mathrm{a}}$ of $\sim 11.3$ and 4.9 respectively (Bazil et al., 2013). While the relatively hydrophobic quinone could be solubilized within the lipid phase for diffusion, the products (ubisemiquinone and uniquinol) would be positioned with their polar head groups outside the lipid phase (Figure 1). Therefore, the products (the actual 
mobile electron carriers of the ETC-CRAS proposal) must translate along the lipid plane by colliding/sliding along with the polar head groups of the membrane phase, and dragging their bulky tail. Such a deterministic journey of quinols from the first pit stop of ETC (Complexes 1/II or Photosystem II) to the next pit stop of CBC would have little thermodynamic drive, other than the mandate of ETC-CRAS scheme. Further, the translation would also be kinetically disadvantaged, with respect to the millisecond scale kinetics of NADH oxidation (oxygen consumption in mitochondria) or NADPH production (oxygen evolution in chloroplasts). For example: the experimentally calculated PQ's diffusion coefficient of $0.01-0.3 \mu \mathrm{m}^{2} / \mathrm{s}$ within thylakoid membranes (Blackwell et al., 1994; Kirchhoff, 2014) gives us a linear displacement of only $\sim 0.1$ to $5 \AA / m s$. This implies that the bulky quinone is practically 'immobile' with respect to the distance separating the protein complexes within the reaction time scales. Similar studies with CoQ had shown that diffusion rate of these molecules within the mitochondrial membrane was low and would be rate limiting for the ETC-CRAS proposal (Chazotte and Hackenbrock, 1989; Gupte et al., 1984). These qualitative considerations and quantitative limitations render the ETC-CRAS hypothesis untenable at the outset.
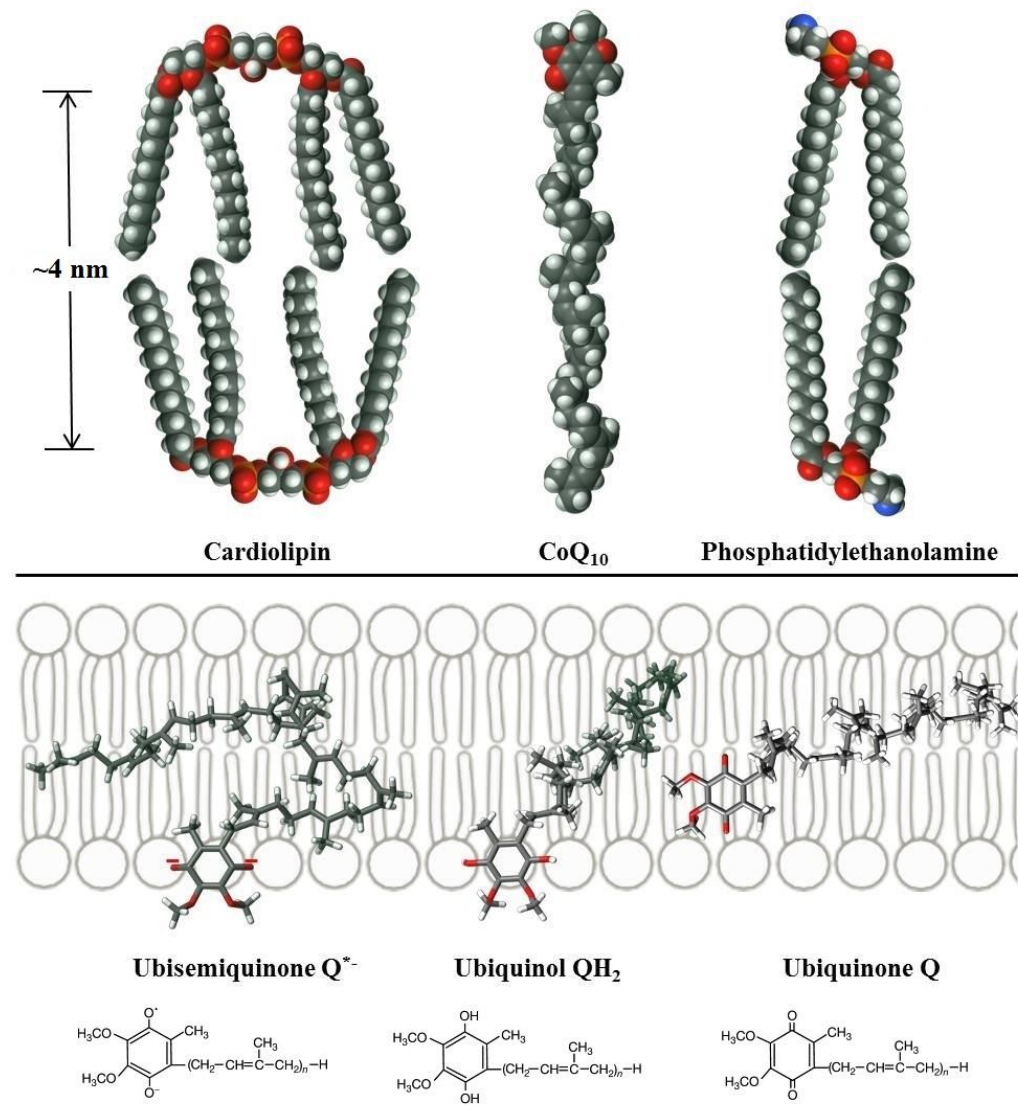
Figure 1: Quinones and lipids in bioenergetic membrane sytems. Structure of CoQ10, PQ9 and comparison with phosphatidyl enthanolamine, cardiolipin, MGDG, other lipids commonly found in mitochondria/chloroplasts. Posturing of quinones and quinols in the lipid bilayer.

In stark contrast, murburn scheme does not require the quinones to be highly mobile or be differentiated at the CBCs. Further, as each protein complex works independently, there is no concept of electron transport chain. The varying lengths of CoQ chains could perhaps enable a better packing within the lipid phase, so as to trap the DROS from escaping out of the matrix. The presence of cardiolipin (Figure 1) with denser negative moiety packing at the periphery is also yet another modality to restrict superoxide dynamics.

Proteins' structure, binding and dynamics with quinones/quinols: Mobile quinones are supposed to interact with three complexes (I, II \& CBC) in the mitochondrial system, two in the chloroplasts (PS II \& CBC) and four in cyanobacteria (I, II, CBC \& PS II). (In this discussion, we shall not concern with Alternate Complex III and Alternate/Terminal Oxidases that also interact with quinols, giving electrons to Cyt. $c$ or oxygen, respectively.) In all these proteins, the precise modalities of interactions are still not clear. For example- (i) The bulkier isoprenoid substituted quinones showed poor docking energies and conformations with Complexes I through III (Manoj et al., 2019a). (ii) Complex I's purported quinone binding site is located several Angstroms into the matrix-ward arm (Sazanov, 2015). It is definitely a deterministic agendum to expect that the quinone head group would squirm its way into the 'protein body' to reach and dock at this site, and detach post the formation of quinol, enabling yet another fresh quinone molecule to dock in lieu. As pointed out earlier (Manoj, 2018b; Manoj et al., 2019b), the quinone binding site should have been on the other side of the trans-membrane foot, and the trans-membrane foot of the protein complex should have had a few redox centers to enable electron transfers through the same, while 'pumping out' protons. Now, there is no imaginable spatio-temporal scope for connecting the physically disconnected proton pumps (an activity that purportedly occurs in millisecond timescales) in the foot region with the electron transfer (which occurs in microsecond timescales) from NADH to CoQ. Also, one wonders how and where from the CoQ finds two protons for making the quinols, deep within the hydrophobic domain of the protein's trans-membrane domain. (ii) Some reviews in the past have vouched that mitochondrial Complex II has two CoQ-binding sites, and therefore, this complex may also be involved in Qcycle (Cecchini, 2003). Even in this protein, it is not known how CoQ could avail protons for 
forming the quinol, post reduction. (iii) Mitochondrial Complex III, with its rather open-dimeric structure, is highly unlikely to serve as an intricate electron circuit, as the ETC-CRAS system espouses. Further, our docking studies and structural analyses had shown that the P-site for binding $\mathrm{CoQH}_{2}$ does not show any preference for its primary substrate, as the purported binding site has only a histidine residue (Manoj et al., 2019a). Further, the electron receiver of heme $b_{\mathrm{L}}$ is too far from the $\mathrm{CoQH}_{2}$ site and it is inconceivable how the reverse circuitry (electrons flowing from $\mathrm{CoQH}_{2}$ back to $\mathrm{CoQ}$ ) can be achieved, as it cannot be achieved in a real 'ETC circuit'. (iv) ETC-CRAS becomes even more non-viable with respect to the newly unraveled structures of supramolecular complexes such as respirasomes (Manoj et al., 2019a), as the CoQ/CoQH2 would have to squirm and navigate through protein frameworks to reach its purported targets/binding sites. (v) It is unimaginable how PQ would collect electrons from Photosystem II located within the deep-seated and appressed thylakoids and deliver them to peripherally located CBC (Manoj et al., 2020b).

There are no major affinity-based demarcating mechanisms between $Q / \mathrm{QH}_{2}$ and the substrate availability is also slow. The murburn model does not seek a serial connectivity and therefore, does not need $\mathrm{CoQH}_{2}$ to move from its source of production to the point of utilization, within the reaction cycle times. We pointed out that the huge matrix-ward distending arm of Complex III was no useless evolutionary baggage in the mitochondrial system, but is an ADP-binding scaffold that enabled efficient DROS dynamics, particularly within respirasome structures (Manoj et al., 2019a). Further, the murburn model for cPhotoPhos does not seek the interthylakoid migration or hopping of PQ molecules. The extra heme in the chloroplasts could be to stabilize the higher density of DROS in this routine.

Proton availability, proton pumping and Q-cycling in the CBCs: As redox enzymologists, we find the Q-cycle 'bizarre', for a multitude of reasons. We have already discussed the 'sophisticated' rationale connected with the outer sphere electron transfer mechanism in detail earlier (Manoj, 2018b). The ETC requires electron bifurcating or switching function at the CBCs and wired circuitry within the protein, among the redox centers. Except for a deterministic supposition, there is no rationale (operable switches or facile connectivity modus) available how or why the protein could or should do this in a repeated fashion. Particularly, given that the redox 
centers are too far apart and are of non-favorable gradients at least during one-leg of the cycle. Earlier suppositions of Fe-S proteins swinging around (Zhang et al., 1998) are too difficult to accept (Hope et al., 1994a; Hope et al., 1994b; Rich et al., 1987; Selak and Whitmarsh, 1982; Whitmarsh et al., 1982). From the time Peter Mitchell first proposed the quinone recycle mechanism to the latest consensus version (Crofts' modified Q-cycle), history witnessed at least half a dozen varying schemes; to make CBCs work independently (Crofts, 2004 a, b). Regardless of all the variant schemes, for both the CBCs, the Mitchellian mass/charge balanced outcome can be schematically captured in Figure 2; and the equation written in two parts and summated as follows:

$\mathrm{QH}_{2(\mathrm{IMM} / \text { Thy.mem. })}+2 \mathrm{Cyt} . c / \mathrm{PC}_{(\mathrm{IMS} / \mathrm{lumen})} \rightarrow \mathrm{Q}_{(\mathrm{IMM} / \text { Thy.mem. })}+2 \mathrm{Cyt} .{ }^{{ }^{-}} / \mathrm{PC}^{{ }^{*}{ }_{-}}$(IMS/lumen) $+2 \mathrm{H}^{+}$(IMS/lumen) $\mathrm{QH}_{2(\mathrm{IMM} / \text { Thy.mem. })}+\mathrm{Q}_{(\mathrm{IMM} / \text { Thy.mem. })}+2 \mathrm{H}_{\text {(matrix/stroma) }}^{+} \rightarrow\left(\mathrm{Q}+\mathrm{QH}_{2}\right)_{(\mathrm{IMM} / \text { Thy.mem. })}+2 \mathrm{H}_{\text {(IMS/lumen) }}^{+}$

$2 \mathrm{QH}_{2}+2 \mathrm{Cyt} . c / \mathrm{PC}+\mathrm{Q}+2 \mathrm{H}^{+}{ }_{\text {(matrix/stroma) }} \rightarrow 2 \mathrm{Q}+2 \mathrm{Cyt} .^{{ }^{*}-} / \mathrm{PC}^{{ }^{*}-}+\mathrm{QH}_{2}+4 \mathrm{H}^{+}{ }_{(\mathrm{IMS} / \text { lumen })}$

$\underline{\mathrm{OR}} \mathrm{QH}_{2}+2 \mathrm{Cyt} . c / \mathrm{PC}+2 \mathrm{H}^{+}{ }_{(\text {matrix/stroma) }} \rightarrow \mathrm{Q}+2 \mathrm{Cyt}_{.}{ }^{{ }^{*}} / \mathrm{PC}^{{ }_{-}}+4 \mathrm{H}^{+}{ }_{(\mathrm{IMS} / \mathrm{lumen})}$

The above equations explain why both CBCs and quinones have been perceived as proton pumps. The classical explanation solicits that matrix/stroma to IMS/lumen and $\mathrm{CoQH}_{2(\mathrm{IMM})} / \mathrm{PQH}_{2(\mathrm{IMM})}$ to IMS/lumen proton pumping machinery should be present. Also, intricate electronic circuitry to bifurcate the electrons from the quinols to two different acceptors present in two different phases must be operational. Prima facie, we pointed out multiple times that there are very little free protons present in the micro-dimensioned organelles to serve the purported proton pumps. Therefore, the Mitchellian cannot start from the initial state itself! Overlooking this fact, the critical minded ones can note two blaring issues at the outset itself, by noting the equations and pictorial depiction. Since the Mitchellian chemiosmotic coupling is a 'closed pot' scheme (as protons have to get crowded in the IMS to build a pmf so that they can re-enter the matrix or stroma), the system would become proton starved in steady state. Next, it makes very little electrochemical or thermodynamic sense that the phase maintained at a positive potential also gets the protons and electrons continuously. Quite simply, this does not make any holistic/dynamic perspective, at a very fundamental level, and therefore, neither the Mitchellian nor modified/activated Q-cycle has any base in reality. 


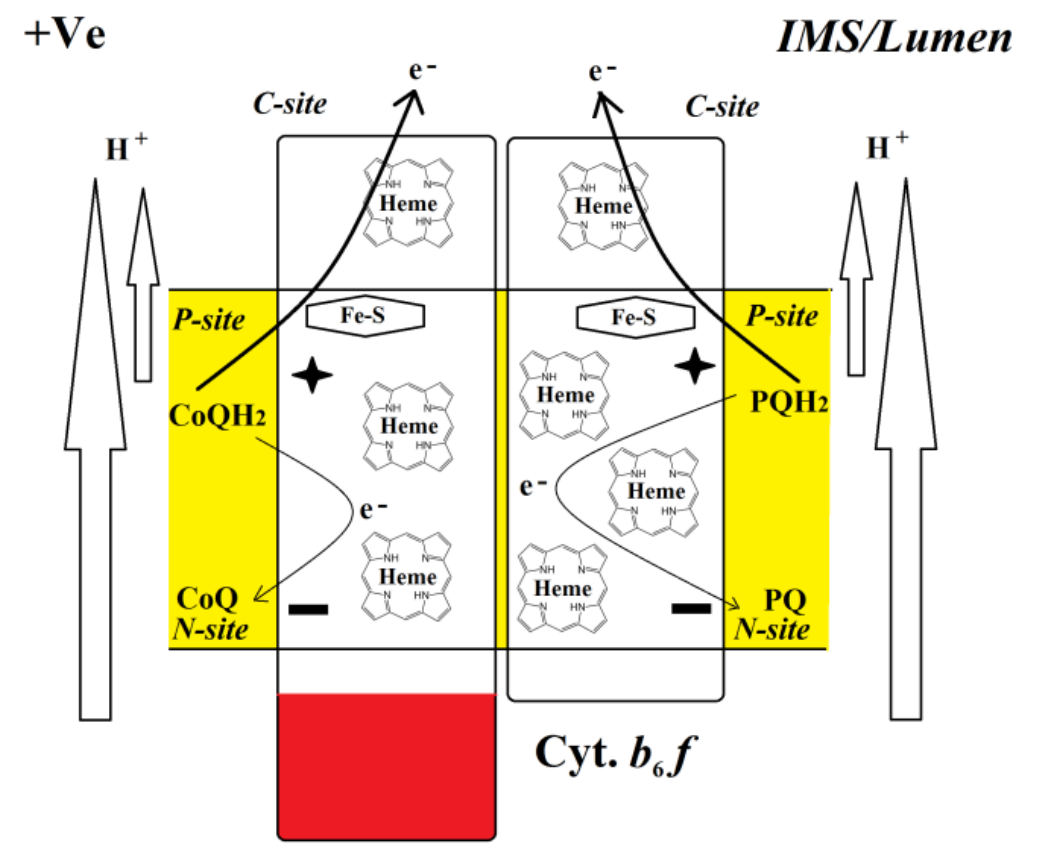

$-\mathrm{Ve}$

Cyt. $b c_{1}$

\section{Matrix/Stroma}

Figure 2: Proton pumps and electron circuitry in CBCs that purportedly carry out the Q-cycle. The relative distances and other details are not marked out for ease in presentation; and only monomers are shown. The membrane is colored yellow and apoprotein portion marked red in Cyt. $b c_{1}$ has no physiological role attributed in ETC-CRAS hypothesis.

Quite contrarily, the murburn scheme for CBCs does not involve proton pumps or electronic circuitries. The semiquinone and fully reduced species can readily react with oxygen (triplet and singlet), giving DROS; which are either harvested in the one-electron scheme at the IMS/lumen side (with Cyt. $c$ or PC) or utilized at the matrix/stomal side as DROS, for NADPH/ATP synthesis. The extra heme in the chloroplast $\mathrm{CBC}$ is to deal with the heavier density of DROS cycling within the system and the bulbous protrusion is CBC's is to serve the mandate of ATP synthesis (Manoj et al. 2019 a,b).

Analyzing the thermodynamics, kinetics and probability of reactions at CBCs: We have discussed the rationale regarding the thermodynamic barriers for outer sphere electron transfers greater than 10 - 15 Angstroms across low or unfavorable redox gradients earlier (Manoj, 2018b). Here, we shall detail (using quantitative yardsticks) some of the other insurmountable odds that the CBC needs to prevail, to carry out the improbable Q-cycle. The yield of CoQ cycle at Cyt. $b c_{1}$ (per the Mitchellian perspective; Voet \& Voet, 2011) is $-36.7 \mathrm{~kJ}$, which agrees with the value of $-35.2 \mathrm{~kJ} / \mathrm{mol}$ we calculated for the overall reaction breakdown, as given by totaling 
the steps 1 through 6 of Table 1. The mass-balance of Mitchellian equations dictates that while one $\mathrm{H}$ atom in $\mathrm{CoQH}_{2}$ can come from $\mathrm{NADH}$ and this proton can be pumped out (given that the yield of Cyt. $b c_{1}$ reaction is more than the required term of $20-22 \mathrm{~kJ} / \mathrm{mol}$ for trans-membrane proton pumping), 3 surplus protons are needed to meet the Mitchellian equation of Cytochrome $b c_{1}$. In chloroplasts, water's photolysis could give two protons for $2 \mathrm{e}$ equivalents, but this too cannot be used for pumping as they are formed in the lumen (whereas the proton pumping is supposed to work from stroma to lumen). We have shown that in the practically aprotic systems such as mitochondria and chloroplasts, the proton-pumping requirement's fulfillment can only be achieved at an energetic expense of $\sim 100 \mathrm{~kJ} / \mathrm{mol}$. Therefore, the Mitchellian caveat of CBCs pumping out four protons per $2 \mathrm{e}$ is a feat which cannot be achieved by both mitochondrial or chloroplastid systems, as the energy terms fall short by almost an order of magnitude!

\begin{tabular}{|c|c|c|c|c|c|c|c|}
\hline No. & Step & From (mV) & Distance (Å) & Time & To (mV) & Yield & Remarks \\
\hline \multicolumn{8}{|c|}{ CoQ cycle at Cyt. $b c_{1}$ in mitochondria $=-\mathbf{3 5 . 2} \mathrm{kJ} / \mathrm{mol}$} \\
\hline 1 & $\mathrm{CoQH}_{2}$ to $\mathrm{FeS}$ & 45 & $>7$ & na & 280 & -45.4 & \\
\hline 2 & FeS to Heme $c_{1}$ & 280 & 21.3 to 31.6 & na & 215 & 6.3 & $x$ \\
\hline 3 & Heme $c_{1}$ to Cyt. $c$ & 215 & $<4$ & na & 235 & -1.9 & \\
\hline 4 & $\mathrm{CoQH}_{2}$ to Heme $b_{\mathrm{lp}}$ & 45 & 12.4 & na & -30 & 14.5 & $x$ \\
\hline 5 & Heme $b_{\mathrm{lp}}$ to Heme $b_{\mathrm{hn}}$ & -30 & 20.5 & na & 30 & -5.8 & $x$ \\
\hline 6 & Heme $b_{\mathrm{hn}}$ to $\mathrm{CoQ}$ & 30 & $<4$ & na & 45 & -2.9 & \\
\hline \multicolumn{8}{|c|}{ PQ cycle at Cyt. $b_{6} f$ complex in chloroplasts (Mulkidjanian, BBA 2010) $=-43.5 \mathrm{~kJ} / \mathrm{mol}$} \\
\hline 7 & $\mathrm{PQH}_{2}$ to $\mathrm{FeS}$ & 80 & 26.4 & $<20 \mathrm{~ms}$ & 335 & -49.2 & $\mathrm{X}$ \\
\hline 8 & FeS to Heme $f$ & 335 & 26.9 & $<1 \mathrm{~ms}$ & 365 & -2.9 & $\mathrm{X}$ \\
\hline 9 & Heme $f$ to $\mathrm{PC}$ & 365 & 16.7 & $<0.15 \mathrm{~ms}$ & 375 & -1.0 & \\
\hline 10 & $\mathrm{PQH}_{2}$ to Heme $b_{\mathrm{lp}}$ & 80 & 16.8 & na & -150 & 44.4 & $x$ \\
\hline 11 & Heme $b_{\mathrm{Ip}}$ to Heme $b_{\mathrm{hn}}$ & -150 & 20.3 & na & -50 & -9.7 & $\mathrm{x}$ \\
\hline 12 & Heme $b_{\mathrm{hn}}$ to $\mathrm{PQ}$ & -50 & 27.1 & na & 80 & -25.1 & $x$ \\
\hline
\end{tabular}

Table 1: Gibbs' free energy change of the individual steps/parts of Q-cycle. As seen, the second leg, 4-6 and 10-12 are energetically non-viable. The terms would end up being different if the semiquinone's (and not quinol) energetics are involved. But in that case, the first cycle's energy terms would be commensurately offset. The steps marked with ' $\mathrm{X}$ ' in the Remarks column signifies unfavorable distance or time factor or redox potential gradients. Values in 1-6: Redox potentials (Voet \& Voet, 2011); Distances (Crofts, 2004a). Values in 7-12: Redox potential/time frames Tschortner et al., 2019; Govindjee et al., 2017; Distances (Malone et al., 2019)

The Mitchellian Q cycle cannot be a functional part of the fast reaction kinetics of oxygen utilization/production seen in mitochondria/chloroplasts, which occur at rates approaching $10^{3}$ per second. This is because Q cycle is known to occur in 10 millisecond timescales, as noted in the apologist's literature (Govindjee and Björn, 2017). For more details on the finer aspects of 
kinetics of various steps in Cyt. c's and PC's interactions with the CBCs, please refer our analyses reported elsewhere (Manoj et al., 2020a).

Disregarding the structural, thermodynamic and kinetic barriers we detailed, we shall avail the optimum conditions to study the probability of reactions. We envisage that the following deterministic sequence (Figure 3) of events must occur for the operability of purported Q-cycle. We shall not allocate any value to ET events (and we shall grant it 100\% viability after achieving the docked state), as we shall grant the outer sphere theory all the benefits. But the state of being bound or unbound would have a score of $1 / 2$ each.

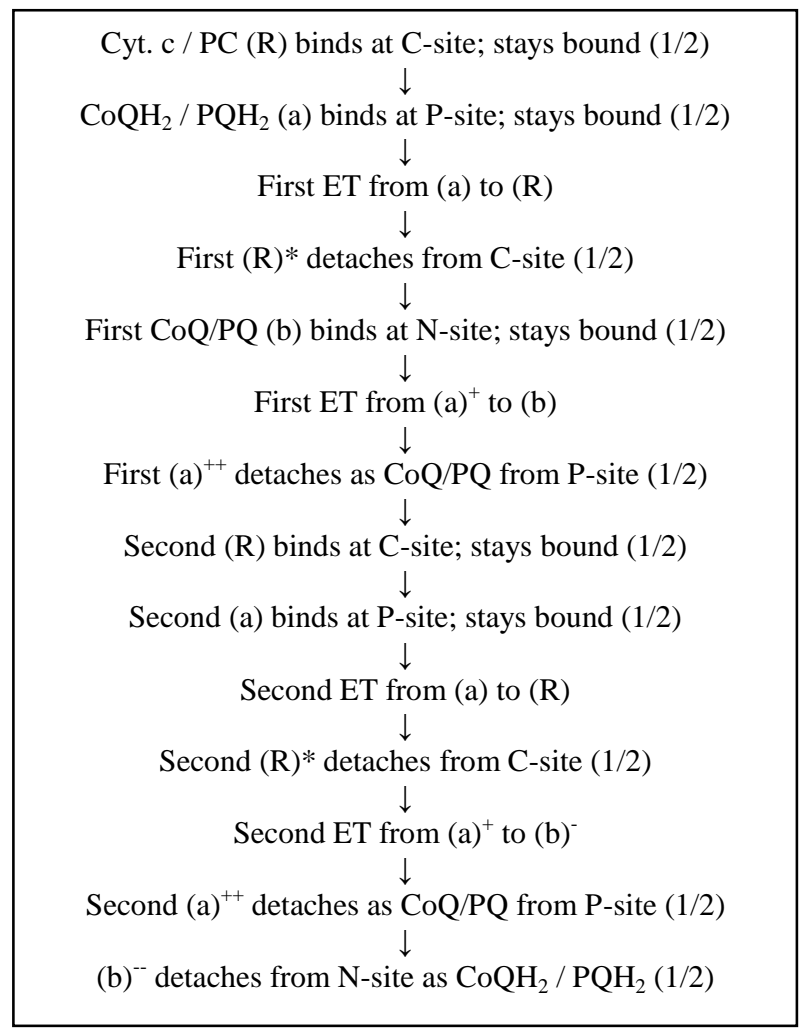

Figure 3: The serial scheme of Q-cycle seeks the realization of a practically impossible set of reactions for achieving a thermodynamically impossible outcome.

The probability is $1 / 1024$ for the Q-cycle alone, discounting other probable disruptive outcomes in ET, when only ten steps were rated. This is when the concentrations of the ligands are below the $\mathrm{K}_{\mathrm{d}}$ and their availability is challenged by mobility/diffusion. The odds are highly stacked against the Mitchellian scheme! 
Once again in stark contrast, mechanistic explanation in the murburn scheme involves bimolecular reactions occurring in parallel, not multi-molecular or sequential/serial. At or around the CBCs, oxygen and quinols/semiquinone have diverse interactions, resetting a one-electron scheme for aiding ATP synthesis or availing reducing power (Figure 4). This accounts for the high mobility/reactivity of oxygen explains the high DROS density at CBCs (Chen et al., 2003) and the ADP binding sites on the same (Manoj et al., 2019a; Manoj et al., 2020c); and also their requirement for efficient ATP synthesis or reducing power generation. The CRAS proposal cannot explain the above three points, besides the lack of structural sophistication to bring out the switching/bifurcation etc. The murbun perspective correctly points out that CBCs serve to regenerate one-electron equivalents back to the reaction milieu so that its potential could be harnessed. So, once the DROS formation process sets in, the probability of favorable outcomes is seldom less than $1 / 4$, considering ATP product formation occurs in two steps (Manoj and Bazhin, 2019).

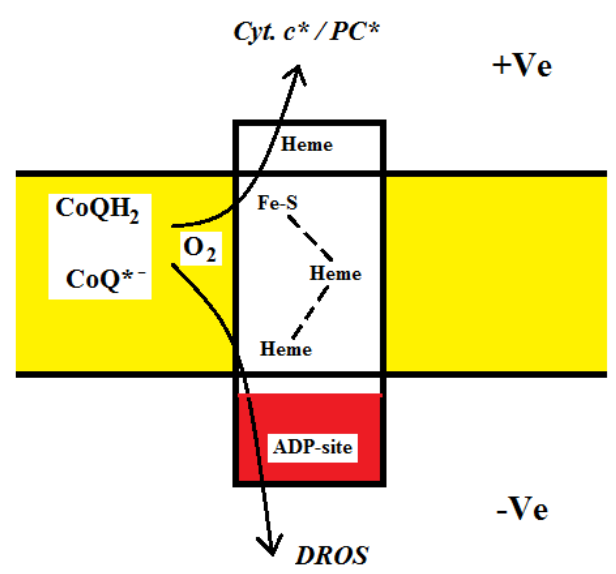

Figure 4: Interactive paradigm of reduced CoQ, oxygen and redox centers of CBCs, as per murburn perspective.

Conclusions: Earlier, we have pointed out serious flaws in Mitchellian assumptions and calculations; particularly how they violate the fundamental laws of thermodynamics (Manoj, 2018a, b). We had also recalculated the energy and equilibrium terms and provided new equations and mechanisms in this regard (Manoj and Nikolai, 2019; Manoj et al., 2019b). Herein, we showed the specific untenable aspects involved with the Q-cycle and contrasted it with the facile scheme of murburn model. The reactions we propose for $\mathrm{CBCs}$ are thermodynamically permitted and kinetically viable, occurring at appreciable timescales as 
compared with the experimentally known values of mOxPhos or cPhotoPhos systems. Hopefully, these discussions pave way for better and more insightful explorations on the roles of CBS in aerobic respiration and oxygenic photosynthesis.

Declarations: The authors have no conflict of interests to declare. The work was powered by Satyamjayatu: The Science \& Ethics Foundation.

\section{References}

Bazil, J.N., Vinnakota, K.C., Wu, F., Beard, D.A., 2013. Analysis of the kinetics and bistability of ubiquinol: cytochrome c oxidoreductase. Biophysical journal 105, 343-355.

Blackwell, M., Gibas, C., Gygax, S., Roman, D., Wagner, B., 1994. The plastoquinone diffusion coefficient in chloroplasts and its mechanistic implications. Biochimica et Biophysica Acta (BBA)-Bioenergetics 1183, 533-543.

Boyer, P.D., 1998. Energy, life, and ATP (Nobel lecture). Angewandte Chemie International Edition 37, 2296-2307.

Cecchini, G., 2003. Function and structure of complex II of the respiratory chain. Annual review of biochemistry 72, 77-109.

Chazotte, B., Hackenbrock, C., 1989. Lateral diffusion as a rate-limiting step in ubiquinonemediated mitochondrial electron transport. Journal of Biological Chemistry 264, 4978-4985.

Chen, Q., Vazquez, E. J., Moghaddas, S., Hoppel, C. L., \& Lesnefsky, E. J. (2003). Production of reactive oxygen species by mitochondria: Central role of Complex III. Journal of Biological Chemistry, 278(38), 36027-36031. doi:10.1074/jbc.M304854200

Cramer, W.A., Hasan, S.S., Yamashita, E., 2011. The Q cycle of cytochrome bc complexes: a structure perspective. Biochimica et Biophysica Acta (BBA)-Bioenergetics 1807, 788-802.

Crofts, A.R., 2004a. The cytochrome bc 1 complex: function in the context of structure. Annu. Rev. Physiol. 66, 689-733.

Crofts, A.R., 2004. The Q-cycle- A personal perspective. Photosyth. Res. 80, 223-243.

Gideon, D.A., Jacob, V.D., Manoj, K.M., 2019. 2020: murburn concept heralds a new era in cellular bioenergetics. Biomedical Reviews 30, 89-98.

Govindjee, S.D., Björn, L., 2017. Evolution of the Z-scheme of photosynthesis: a perspective. Photosynth. Res 133, 5-15.

Gupte, S., Wu, E.-S., Hoechli, L., Hoechli, M., Jacobson, K., Sowers, A.E., Hackenbrock, C.R., 1984. Relationship between lateral diffusion, collision frequency, and electron transfer of mitochondrial inner membrane oxidation-reduction components. Proceedings of the National Academy of Sciences 81, 2606-2610.

Hope, A., Matthews, D., Valente, P., 1994a. The kinetics of reactions around the cytochrome bf complex studied in an isolated system. Photosynthesis research 40, 199-206. 
Hope, A., Valente, P., Matthews, D., 1994b. Effects of $\mathrm{pH}$ on the kinetics of redox reactions in and around the cytochromebf complex in an isolated system. Photosynthesis Research 42, 111120.

Kirchhoff, H., 2014. Diffusion of molecules and macromolecules in thylakoid membranes. Biochimica et Biophysica Acta (BBA)-Bioenergetics 1837, 495-502.

Malone, L.A., Qian, P., Mayneord, G.E., Hitchcock, A., Farmer, D.A., Thompson, R.F., Swainsbury, D.J., Ranson, N.A., Hunter, C.N., Johnson, M.P., 2019. Cryo-EM structure of the spinach cytochrome b 6 f complex at $3.6 \AA ̊$ resolution. Nature 575, 535-539.

Manoj, K.M., 2017. Debunking Chemiosmosis and proposing murburn concept as the operative principle for cellular respiration. Biomedical Reviews. 28, 31-48.

Manoj, K.M., 2018a. Aerobic Respiration: criticism of the proton-centric explanation involving rotary adenosine triphosphate synthesis, chemiosmosis principle, proton pumps and electron transport chain. Biochemistry Insights 11, 1178626418818442.

Manoj, K.M., 2018b. The ubiquitous biochemical logic of murburn concept. Biomedical Reviews 29, 89-97.

Manoj, K.M., Gideon, D.A., Jacob, V.D., 2018. Murburn scheme for mitochondrial thermogenesis. Biomedical Reviews 29, 73-82.

Manoj, K.M., Parashar, A., David Jacob, V., Ramasamy, S., 2019a. Aerobic respiration: proof of concept for the oxygen-centric murburn perspective. Journal of Biomolecular Structure and Dynamics 37, 4542-4556.

Manoj, K.M., Soman, V., Jacob, V.D., Parashar, A., Gideon, D.A., Kumar, M., Manekkathodi, A., Ramasamy, S., Pakshirajan, K., Bazhin, N.M., 2019b. Chemiosmotic and murburn explanations for aerobic respiration: predictive capabilities, structure-function correlations and chemico-physical logic. Archives of biochemistry and biophysics 676, 108128.

Manoj, K.M., 2019c. Torday's prognosis for aging and mortality: more evolution and better life! Biomedical Reviews 30, 23-24.

Manoj, K.M., Nikolai, B., 2019c. Murburn precepts of aerobic respiration. DOI: 10.31219/osf.io/hx4p9

Manoj, K.M., Bazhin N., 2019. Murburn precepts of aerobic respiration. OSF Preprints, DOI: 10.31219/osf.io/hx4p9.

Manoj, K.M., 2020a. Critical analysis of some assumptions and observations on photolytic oxygenesis by plant cells. OSF Preprints, DOI: 10.31219/osf.io/y62j5.

Manoj, K.M., 2020b. Murburn concept: a paradigm shift in cellular metabolism and physiology. Biomolecular Concepts 11, 7-22.

Manoj, K.M., Nikolai, B., Parashar, A., Gideon, D.A., Jacob, V.D., Haarith, D., Manekkathodi, A., 2020c. Murburn precepts for the light reaction of oxygenic photosynthesis. OSF Preprints, DOI: $10.31219 /$ osf.io/95brg.

Manoj, K.M., Gideon, D.A., Jacob, V.D., Haarith, D., Manekkathodi, A., 2020d. Is Z-scheme a tenable explanation for the light reaction of oxygenic photosynthesis? OSF Preprints, DOI: 10.31219/osf.io/v6tdf. 
Manoj, K.M., Ramasamy, S., Parashar, A., Gideon, D.A., Soman, V., Jacob, V.D., Pakshirajan, K., 2020e. Acute toxicity of cyanide in aerobic respiration: Theoretical and experimental support for murburn explanation. Biomolecular Concepts 11, 32-56.

Manoj, K., Nirusimhan, V., Gideon, D., 2020f. Are plastocyanin and ferredoxin specific electron carriers or generic redox capacitors? Classical and murburn perspectives on two chloroplast proteins. OSF Preprints, DOI: 10.31219/osf.io/j7q5v.

Manoj, K.M., Manekkathodi, A., 2020. Light's interaction with pigments in chloroplasts: The murburn perspective. OSF Preprints, 10.31219/osf.io/wx4gv.

Manoj, K.M., Soman, V., 2020. Classical and murburn explanations for acute toxicity of cyanide in aerobic respiration: A personal perspective. Toxicology 432, 152369.

Mitchell, P., 1979. David Keilin's respiratory chain concept and its chemiosmotic consequences Nobel Lecture, 8 December, 1978. Les Prix Nobel, 137.

Nałęcz, M.J., 1986. Is there sufficient experimental evidence to consider the mitochondrial cytochromebc 1 complex a proton pump? Probably no. Journal of bioenergetics and biomembranes 18, 21-38.

Osman, C., Voelker, D.R., Langer, T., 2011. Making heads or tails of phospholipids in mitochondria. Journal of Cell Biology 192, 7-16.

Perkins, G., Renken, C., Martone, M., Young, S., Ellisman, M., Frey, T., 1997. Electron tomography of neuronal mitochondria: three-dimensional structure and organization of cristae and membrane contacts. Journal of structural biology 119, 260-272.

Rich, P.R., Heathcote, P., Moss, D.A., 1987. Kinetic studies of electron transfer in a hybrid system constructed from the cytochrome bf complex and photosystem I. Biochimica et Biophysica Acta (BBA)-Bioenergetics 892, 138-151.

Sazanov, L.A., 2015. A giant molecular proton pump: structure and mechanism of respiratory complex I. Nature Reviews Molecular Cell Biology 16, 375-388.

Schaller, S., Latowski, D., Jemioła-Rzemińska, M., Wilhelm, C., Strzałka, K., Goss, R., 2010. The main thylakoid membrane lipid monogalactosyldiacylglycerol (MGDG) promotes the deepoxidation of violaxanthin associated with the light-harvesting complex of photosystem II (LHCII). Biochimica et Biophysica Acta (BBA)-Bioenergetics 1797, 414-424.

Selak, M., Whitmarsh, J., 1982. Kinetics of the electrogenic step and cytochrome b6 and f redox changes in chloroplasts: Evidence for a Q cycle. FEBS letters 150, 286-292.

Whitmarsh, J., Bowyer, J.R., Crofts, A.R., 1982. Modification of the apparent redox reaction between cytochrome $f$ and the Rieske iron-sulfur protein. Biochimica et Biophysica Acta (BBA)Bioenergetics 682, 404-412.

Zhang, Z., Huang, L., Shulmeister, V.M., Chi, Y.-I., Kim, K.K., Hung, L.-W., Crofts, A.R., Berry, E.A., Kim, S.-H., 1998. Electron transfer by domain movement in cytochrome bc 1. Nature 392, 677-684. 


\title{
Supplementary Information
}

\section{What is the role of lipid membrane-embedded quinones in ATP-synthesis? Chemiosmotic $Q$-cycle versus murburn reaction perspective}

\author{
Kelath Murali Manoj ${ }^{1}$ *, Daniel Andrew Gideon ${ }^{1}$, Abhinav Parashar ${ }^{2} *$
}

\begin{abstract}
*Corresponding author, ${ }^{1}$ Satyamjayatu: The Science \& Ethics Foundation, Kulappully, Shoranur-2 (PO), Palakkad District, Kerala State, India-679122.

Email: satyamjayatu@yahoo.com
\end{abstract}

*Corresponding author, ${ }^{2}$ Department of Biotechnology,

Vignan's Foundation for Science, Technology \& Research, Vadlamudi, Guntur, India-522213.

How six decades of chemiosmosis has sent scientists on vain consensus seeking exercises! 
Mitchell said that Comp. IV is not a proton pump!

Volume 88, number 2

FEBS LETTERS

April 1978

\author{
CYTOCHROME $c$ OXIDASE IS NOT A PROTON PUMP \\ Jennifer MOYLE and Peter MITCHELL \\ Glynn Research Laboratories, Bodmin, Cornwall, PL30 4AU, Engiand
}

Received 23 January 1978

\section{Introduction}

Mitchell postulated that cytochrome $c$ oxidase is plugged through the coupling membrane of mitochondria and bacteria so that the reduction of $\mathrm{O}_{2}$ to $2 \mathrm{H}_{2} \mathrm{O}$ involves the translocation of $4 \mathrm{e}^{-}$from cytochrome $c$ at the outer surface of the membrane to $4 \mathrm{H}^{+}$ions that enter the reaction domain from the inner aqueous phase [1]. As evidence for this putative matter whether $\mathrm{O}_{2}$ or ferricyanide was used as oxidant [2] . As ferricyanide is impermeant and oxidises cytochrome $c$, bypassing cytochrome $c$ oxidase, we concluded that cytochrome $c$ oxidase does not act as a proton pump, but catalyses only the net translocation of electrons [3]. Work by Hinkle, Papa, Racker and others, using mitochondria, sonically-prepared mitochondrial vesicles and liposomes inlaid with cytochrome $c$ oxidase has greatly strength-

\title{
Nałęcz said Complex III is not a proton pump!
}

Journal of Bioenergetics and Biomembranes, Vol. 18, No. 1, 1986

\section{MINI REVIEW}

\section{Is There Sufficient Experimental Evidence to Consider the Mitochondrial Cytochrome $b c_{1}$ Complex a Proton Pump? Probably No. ${ }^{1}$}

\author{
Maciej J. Nałęcz ${ }^{2}$
}

Received October 8, 1985 


\section{The dichotomy of complex I: A sodium ion pump or a proton pump}

Judy Hirst*

Medical Research Council, Dunn Human Nutrition Unit, Wellcome Trust/MRC Building, Hills Road, Cambridge CB2 2XY, United Kingdom

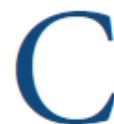

omplex I (NADH/quinone oxidoreductase) is the only enzyme of the membrane-bound respiratory chain to remain a "black box." Atomic resolution structural models are available for three of the four energy-transducing respiratory complexes: the cytochrome $b c_{1}$ complex, cytochrome oxidase, and the $\mathrm{F}_{1}$ domain of ATP synthase. Detailed mechanisms that integrate these structural models with the results of spectroscopic and functional studies are therefore being constructed (1). In comparison, due to its large size and subunit complexity, and because its cofactors are difficult to distinguish spectroscopically, complex I has proved intractable. The complex is prise the simpler bacterial enzymes (9) and therefore are deemed sufficient for catalysis and energy transduction. The core subunit conservation and homology suggest that all complexes I operate by a common mechanism. However, if bovine complex I pumps four protons across the membrane for each NADH oxidized but complex I from $K$. pneumoniae pumps two sodium ions (10), then this conclusion must be questioned. These different cation specificities and stoichiometries have fundamental implications for our understanding of the mechanism of complex I and its role in energy transduction and metabolism, and challenge the relevance of bacterial complexes I as models for the mamma- allow meaningful sequence comparisons to be drawn, and these may help to identify the cation-binding sites. A similar approach was employed successfully for ATP synthase (11): most ATP synthases use a proton motive force, but closely related examples that use a sodium ion motive force have been identified in bacteria such as Propionigenium modestum. A family of sodium ion/proton antiporters identified in alkaliphilic bacteria contain stretches of sequence similarity with the membrane-bound ND2, 4, and 5 (NuoN, -M, and -L) subunits of complex I $(12,13)$. On this basis, these subunits have been proposed to bind cations and to constitute a conforma-

\section{Sazanov says Comp. I is a proton pump!}

\section{A giant molecular proton pump: structure and mechanism of respiratory complex I}

Leonid A. Sazanov

Abstract | The mitochondrial respiratory chain, also known as the electron transport chain (ETC), is crucial to life, and energy production in the form of ATP is the main mitochondrial function. Three proton-translocating enzymes of the ETC, namely complexes I, III and IV, generate proton motive force, which in turn drives ATP synthase (complex V). The atomic structures and basic mechanisms of most respiratory complexes have previously been established, with the exception of complex I, the largest complex in the ETC. Recently, the crystal structure of the entire complex I was solved using a bacterial enzyme. The structure provided novel insights into the core architecture of the complex, the electron transfer and proton translocation pathways, as well as the mechanism that couples these two processes. 


\section{Voet's Biochemistry (Comp. I = 4, CoQ $=4$, Comp. IV = 2)}

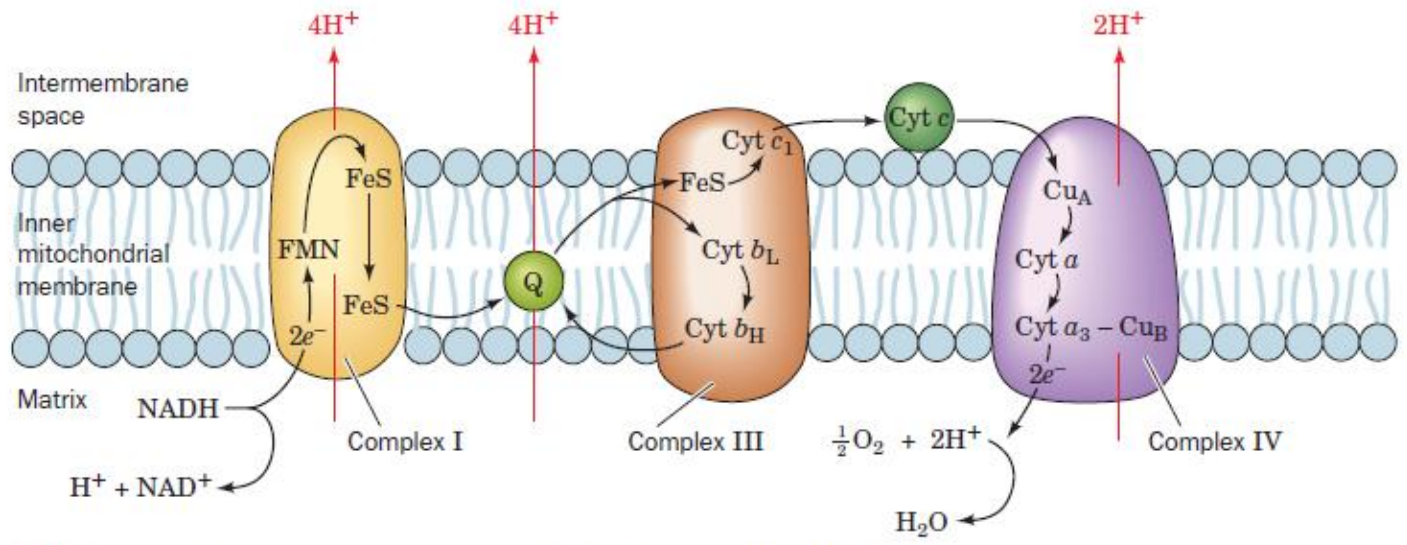

Figure 22-14 The mitochondrial electron-transport chain. The pathways of electron transfer (black) and proton pumping (red) are indicated. Electrons are transferred between Complexes I and III by membrane-soluble CoQ (Q) and between Complexes

III and IV by the peripheral membrane protein cytochrome $c$ (Cyt $c$ ). Complex II (not shown) transfers electrons from succinate to CoQ. See the Animated Figures

\section{Lehningers' Principles of Biochemistry (Comp. I = 4, Comp. III = 4, Comp. IV = 2)}

\section{(Same as Garret and Grisham's \& Stryer's textbooks)}

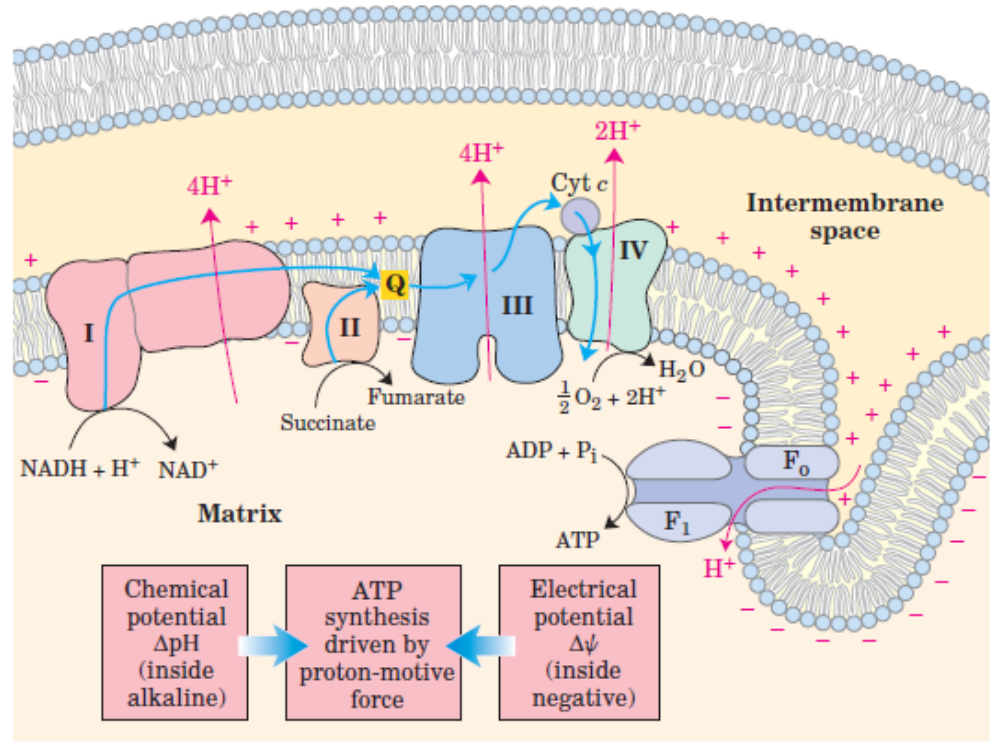

FIGURE 19-17 Chemiosmotic model. In this simple representation of the chemiosmotic theory applied to mitochondria, electrons from NADH and other oxidizable substrates pass through a chain of carriers arranged asymmetrically in the inner membrane. Electron flow is accompanied by proton transfer across the membrane, producing both a chemical gradient $(\Delta \mathrm{pH})$ and an electrical gradient $(\Delta \psi)$. The inner mitochondrial membrane is impermeable to protons; protons can reenter the matrix only through proton-specific channels $\left(F_{o}\right)$. The proton-motive force that drives protons back into the matrix provides the energy for ATP synthesis, catalyzed by the $F_{1}$ complex associated with $\mathrm{F}_{\mathrm{o}}$. 


\section{Metzler's Biochemistry (Comp. I = 4, Comp. III = 4, Comp. IV = 4)}

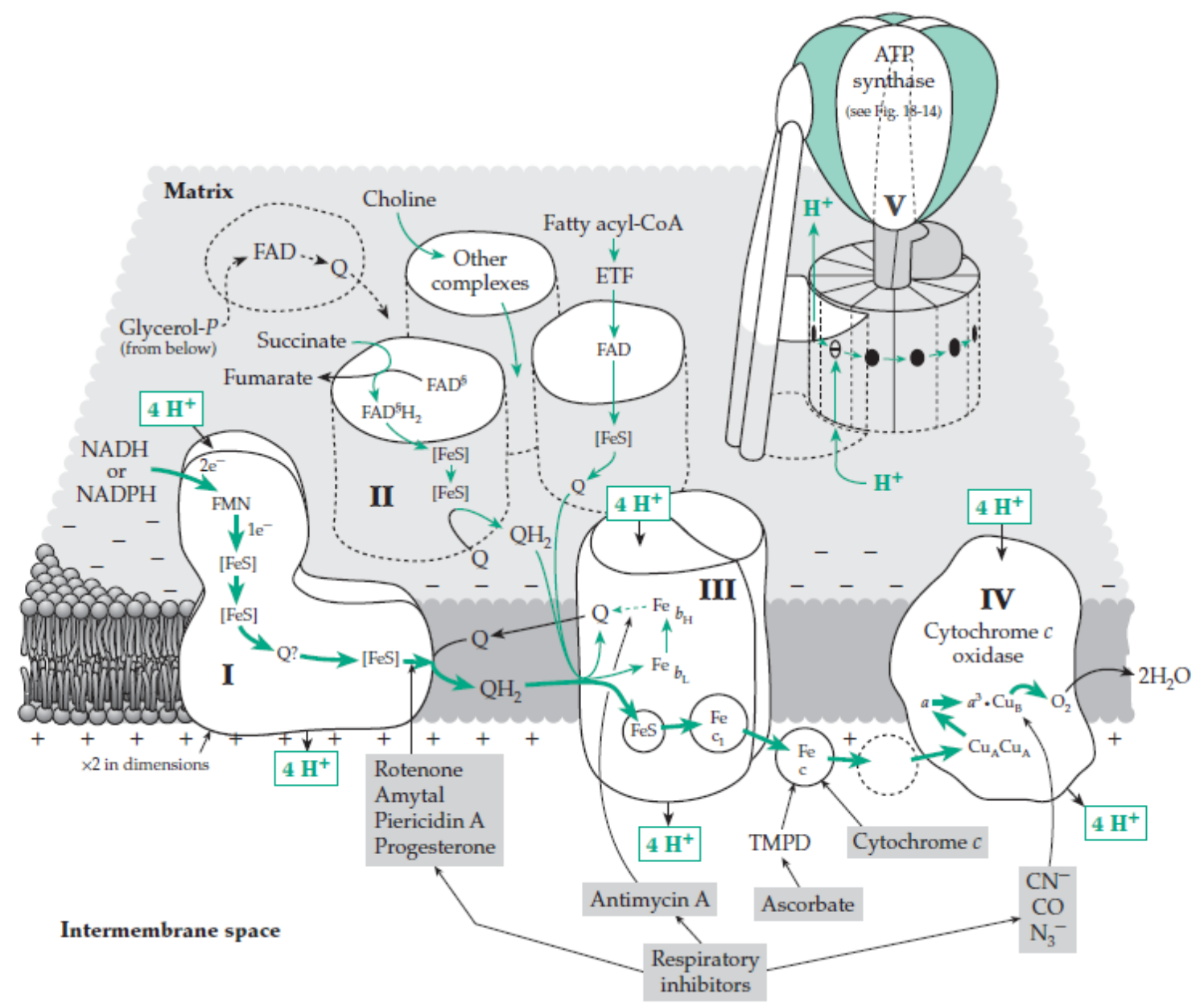

Figure 18-5 A current concept of the electron transport chain of mitochondria. Complexes I, III, and IV pass electrons from NADH or NADPH to $\mathrm{O}_{2}$, one NADH or two electrons reducing one $\mathrm{O}$ to $\mathrm{H}_{2} \mathrm{O}$. This electron transport is coupled to the transfer of about $12 \mathrm{H}^{+}$from the mitochondrial matrix to the intermembrane space. These protons flow back into the matrix through ATP synthase (V), four $\mathrm{H}^{+}$driving the synthesis of one ATP. Succinate, fatty acyl-CoA molecules, and other substrates are oxidized via complex II and similar complexes that reduce ubiquinone $Q$, the reduced form $\mathrm{QH}_{2}$ carrying electrons to complex III. In some tissues of some organisms, glycerol phosphate is dehydrogenated by a complex that is accessible from the intermembrane space. 
Leading "authorities" change their numbers at their own jolly wanton whims!

Wikstrom, PNAS 2012 (Comp. I = 3, Comp. III = 2, Comp. IV = 4)

Table 1. Conversion of measured ATP $/ 2 \mathrm{e}^{-}$ratios to proton translocation stoichiometries in respiratory chain of rat-liver mitochondria

\begin{tabular}{lcc} 
Complex & ATP $/ 2 \mathrm{e}^{-}$ & $\mathrm{H}^{+} / 2 \mathrm{e}^{-}$(efficiency, \%) \\
\hline I + III + IV & $2.27 \pm 0.08$ & $8.32(92 \%)$ \\
III + IV & $1.48 \pm 0.04$ & $5.43(91 \%)$ \\
III & $0.49 \pm 0.02$ & $1.80(90 \%)$ \\
IV & $0.98 \pm 0.09$ & $3.59(90 \%)$ \\
I (I + III + IV minus III + IV) & 0.79 & $2.90(97 \%)$ \\
I (I + III + IV minus III minus IV) & 0.80 & $2.90(97 \%)$ \\
\hline
\end{tabular}

The ATP $/ 2 \mathrm{e}^{-}$ratios are from Hinkle et al. (20) for rat-liver mitochondria oxidizing $\beta$ - $\mathrm{OH}$-butyrate $(\mathrm{I}+\mathrm{III}+\mathrm{IV})$ or succinate $(\mathrm{III}+\mathrm{IV})$ by $\mathrm{O}_{2}$, succinate by ferricyanide (III), or TMPD (+ascorbate) by $\mathrm{O}_{2}$ (IV). The $\mathrm{H}^{+} / 2 \mathrm{e}^{-}$ratios are derived from the ATP $/ 2 \mathrm{e}^{-}$ratio using Eq. 4 and a value of 3.67 for the $\mathrm{H}^{+}$/ATP ratio. Per cent efficiency is reported for the assumption that the effective mechanistic $\mathrm{H}^{+} / 2 \mathrm{e}^{-}$stoichiometries' are 3, 2, and 4, respectively, for complexes I, III, and IV (i.e., 9 for I+ III + IV and 6 for III+IV). The two ATP $/ 2 \mathrm{e}^{-}$ratios for complex $\mathrm{I}$ are derived from the measured ratios, as indicated.

Wikstrom, Chem Rev 2015 (Comp. I = 3-4, Comp. III = 4, Comp. IV = 2)

\section{Complex I}

Complex III

Complex IV

Complex V

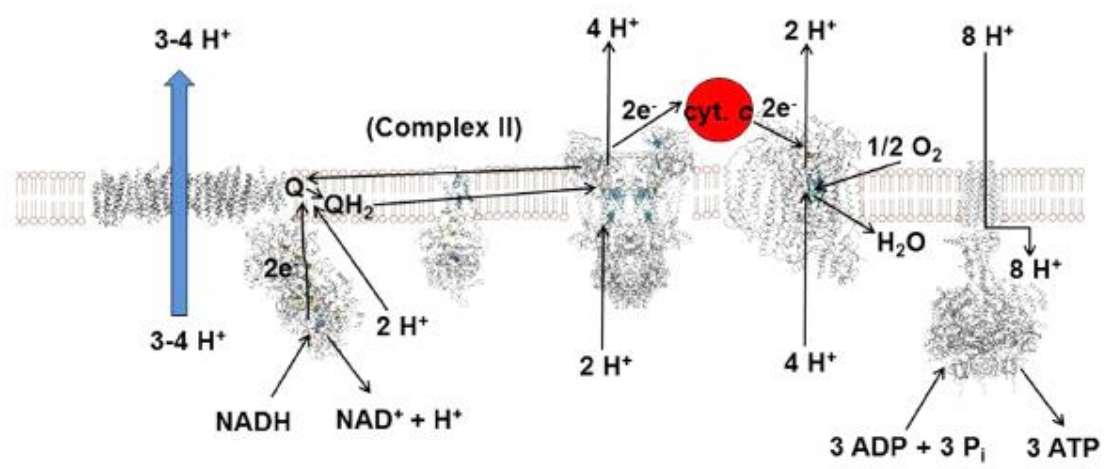

Figure 1. Respiratory chain and ATP synthase. The respiratory chain is depicted in a phospholipid membrane, as it is found in most mitochondria and in many bacteria. ATP synthase is shown to translocate 8 protons per 3 synthesized ATP molecules, as observed in animal mitochondria. 
The ways in which the number of protons are transferred/cycled are also different!

Sazanov's Q mechanism, Nature Reviews, 2015

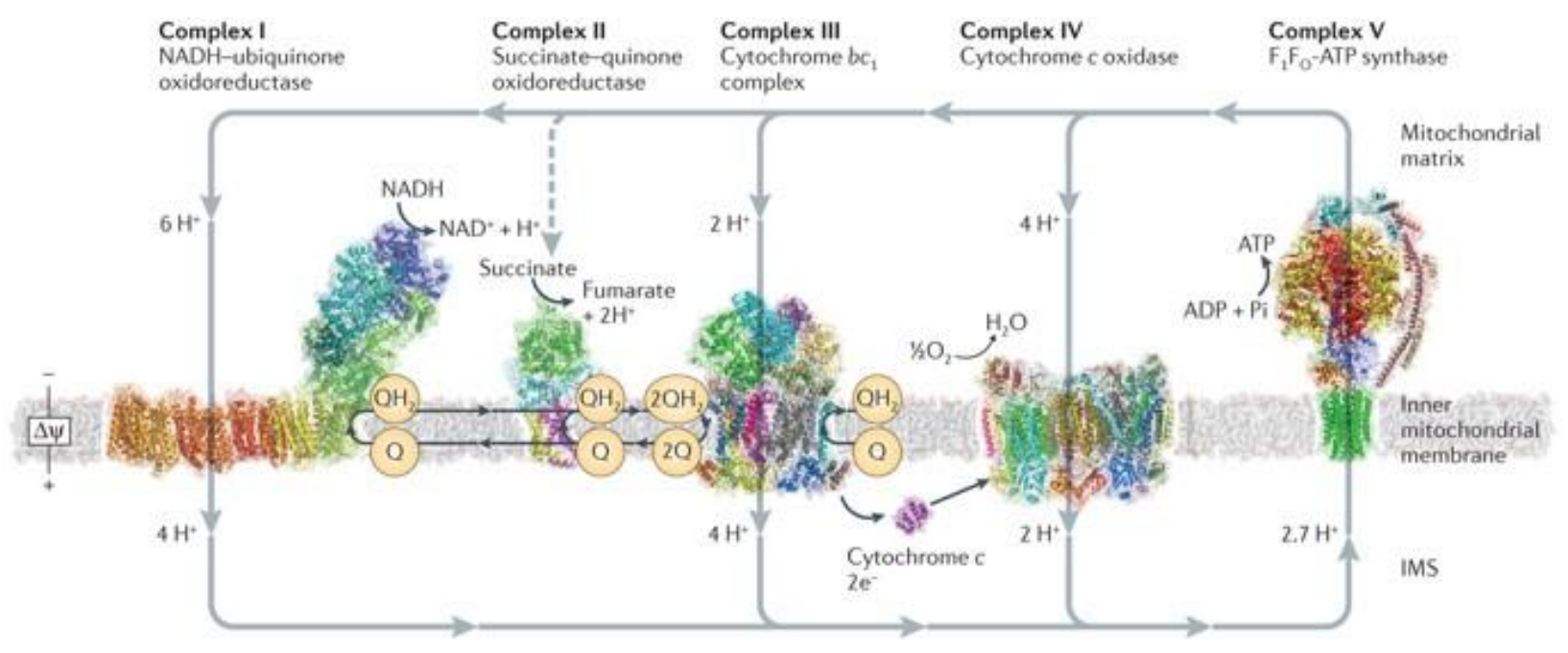

Nature Reviews | Molecular Cell Biology

Antony Crofts's Q mechanism (his website: https://www.life.illinois.edu/crofts/bioph354/lect8.html)

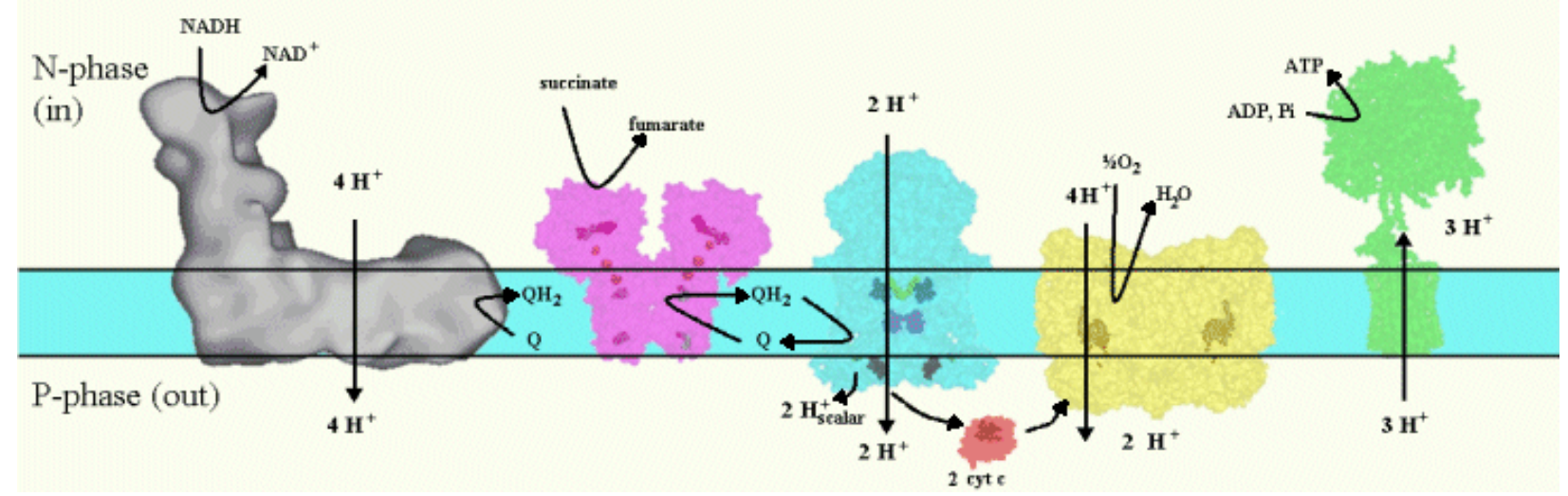


Some reputed Chinese researchers' publications-

Sun F et al. (Rao Zihe group) Curr. Opin. Str. Biol., 2013 (Comp. I = 4, Comp. III = 4, Comp. IV = 2)

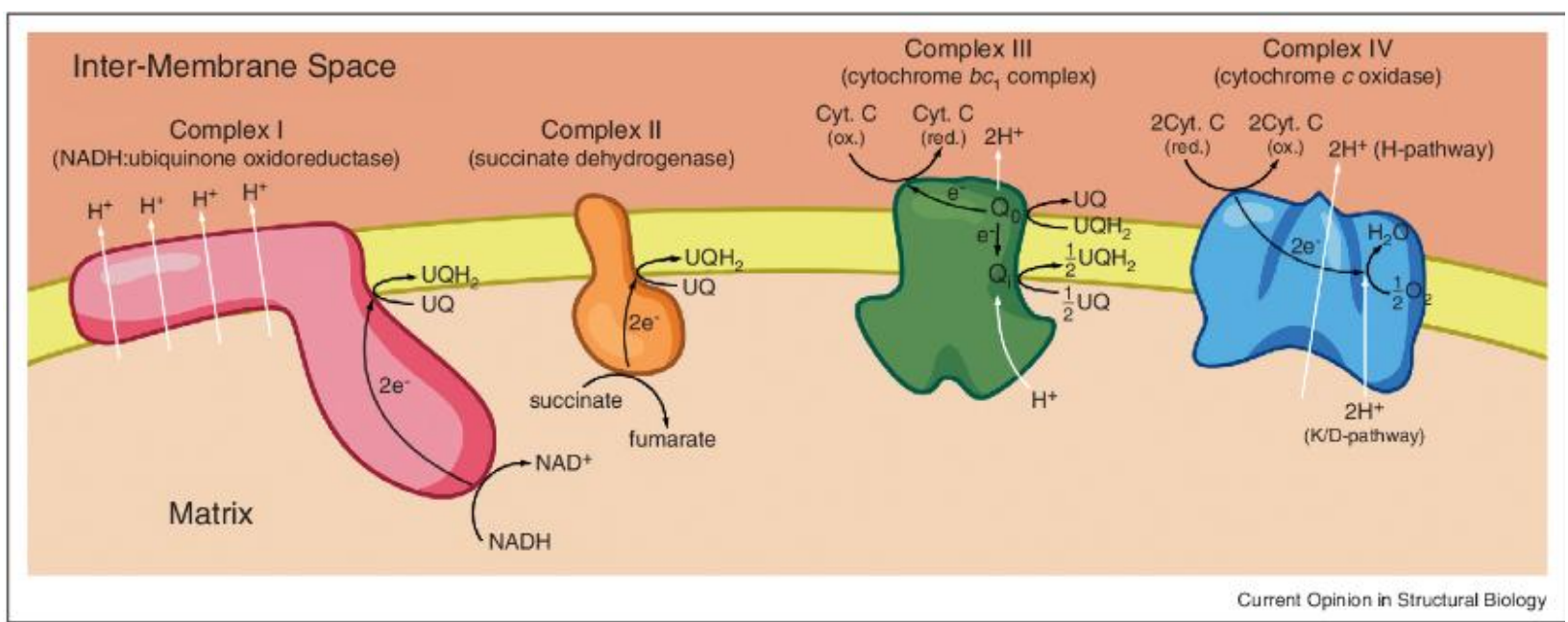

Zhao R-Z et al. (Zhi-Bin Yu group), Int. J. Mol. Med., 2019 (Comp. I = 2, Comp. III = 4, Comp. IV = 4)

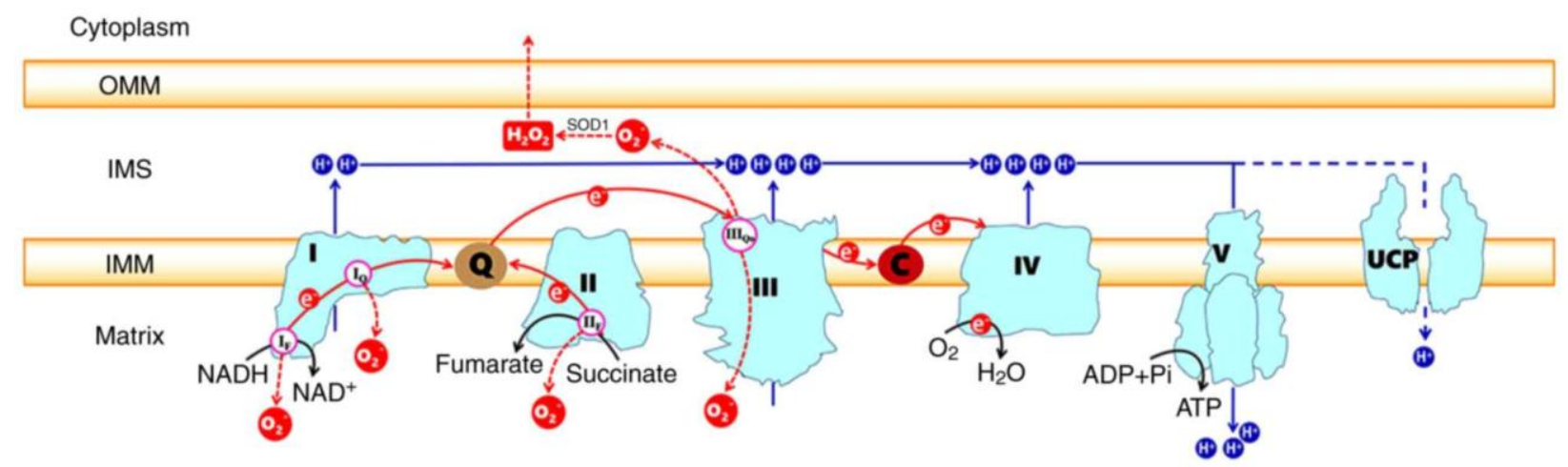

Figure 1 - Generation of electron leaks and proton leaks in the electron transport chain. Electrons derived from oxidizable substrates are passed through CI/III/IV or CII/III/IV in an exergonic process that drives the proton pumping into the IMS of CI, CIII and CIV. The energy of the proton gradient drives the ATP synthesis of CV or can be consumed by UCPs. The sites of superoxide production in each complex are also indicated, including sites IF and IQ in CI, sites IIF in CII and site IIIQo in CIII. The O -2 released into the IMS by site IIIQo can be converted into $\mathrm{H} 2 \mathrm{O} 2$ in a reaction catalyzed by superoxide dismutase 1 and $\mathrm{H} 2 \mathrm{O} 2$ then may diffuse into the cytoplasm. 
Olivier Biner et al., Chimia, 2018 (Comp. I = 4, Comp. III = 2, Comp. IV = 4)

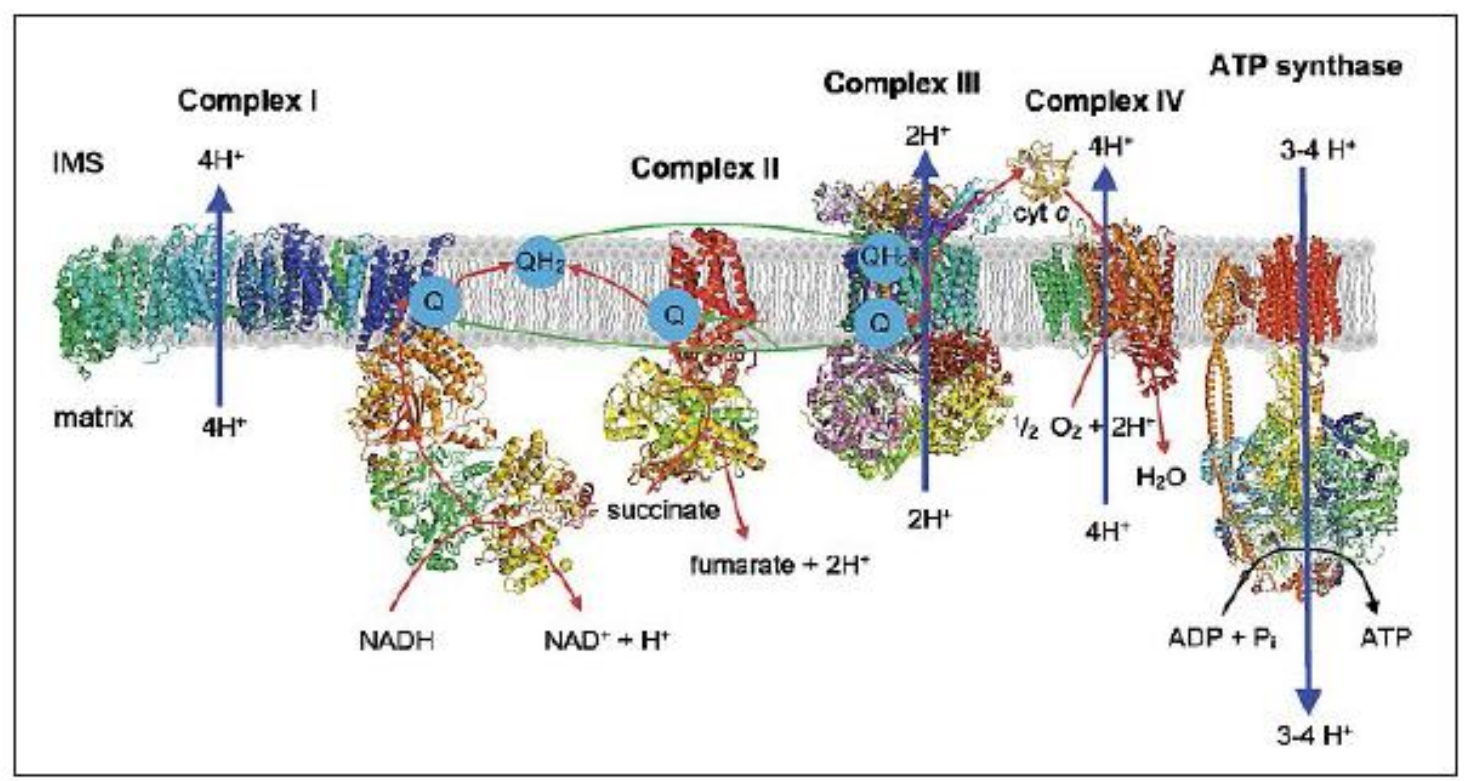

Fig. 1. Schematic representation of the respiratory chain in a mitochondrion. Complex I (PDB: 4 WZ7) oxidizes $N A D H$ to $N A D^{+}$to reduce ubiquinone $(\mathrm{Q})$ to ubiquinol $\left(\mathrm{QH}_{2}\right)$. The electron transfer is coupled to the transport of four protons from the mitochondrial matrix to the inner membrane space (IMS). Complex II (PDB: 2WDV) oxidizes succinate to fumarate and reduces Q without proton translocation. The electrons are then transferred from $\mathrm{QH}_{2}$ to cytochrome $c$ via complex III accompanied by the translocation of two protons. Finally, four molecules of cytochrome $c$ are used to reduce oxygen to water in complex IV coupled to the transport of four protons. Overall, a total of ten protons are translocated across the mitochondrial membrane per NADH oxidized. The electrochemical proton gradient is dissipated by the ATP synthase to generate ATP. Electron and proton transfer processes are depicted with red and blue arrows, respectively.

Lewis MT - Kasper JD - Bazil JN - Frizbee JC - Wiseman RW, Int. J. Mol. Sci., 2019 (Comp. I = 4, Comp. III = 2, Comp. IV = 4)

\section{INTERMEMBRANE SPACE}

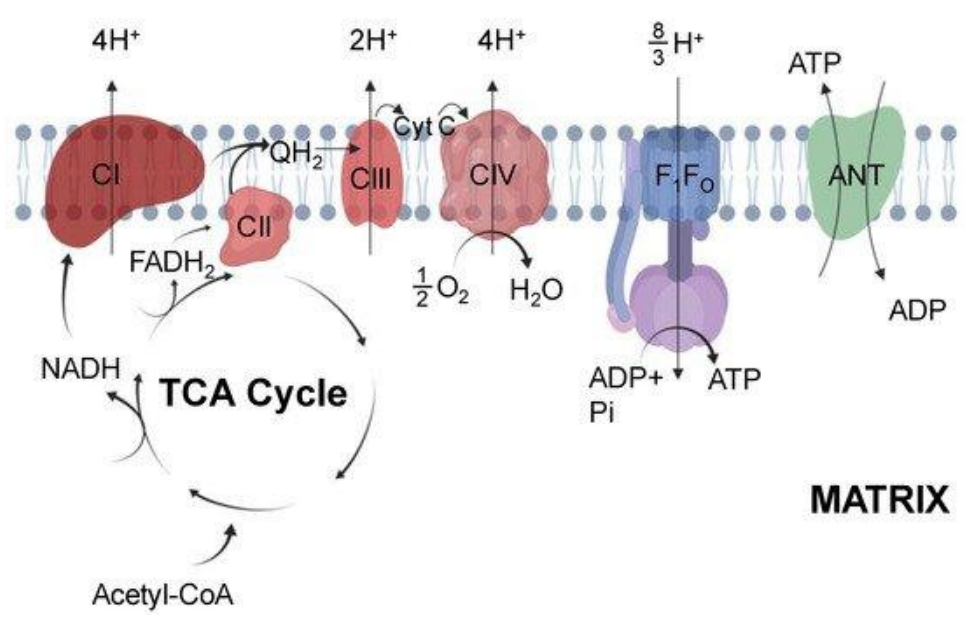


Same status in chloroplast ETC-CRAS!!

https://bio.libretexts.org/Bookshelves/Biochemistry/Book\%3A_Biochemistry_Free_For_All_(Ahern\%2C_ Rajagopal\%2C_and_Tan)/05\%3A_Energy/5.03\%3A_Energy_-_Photophosphorylation

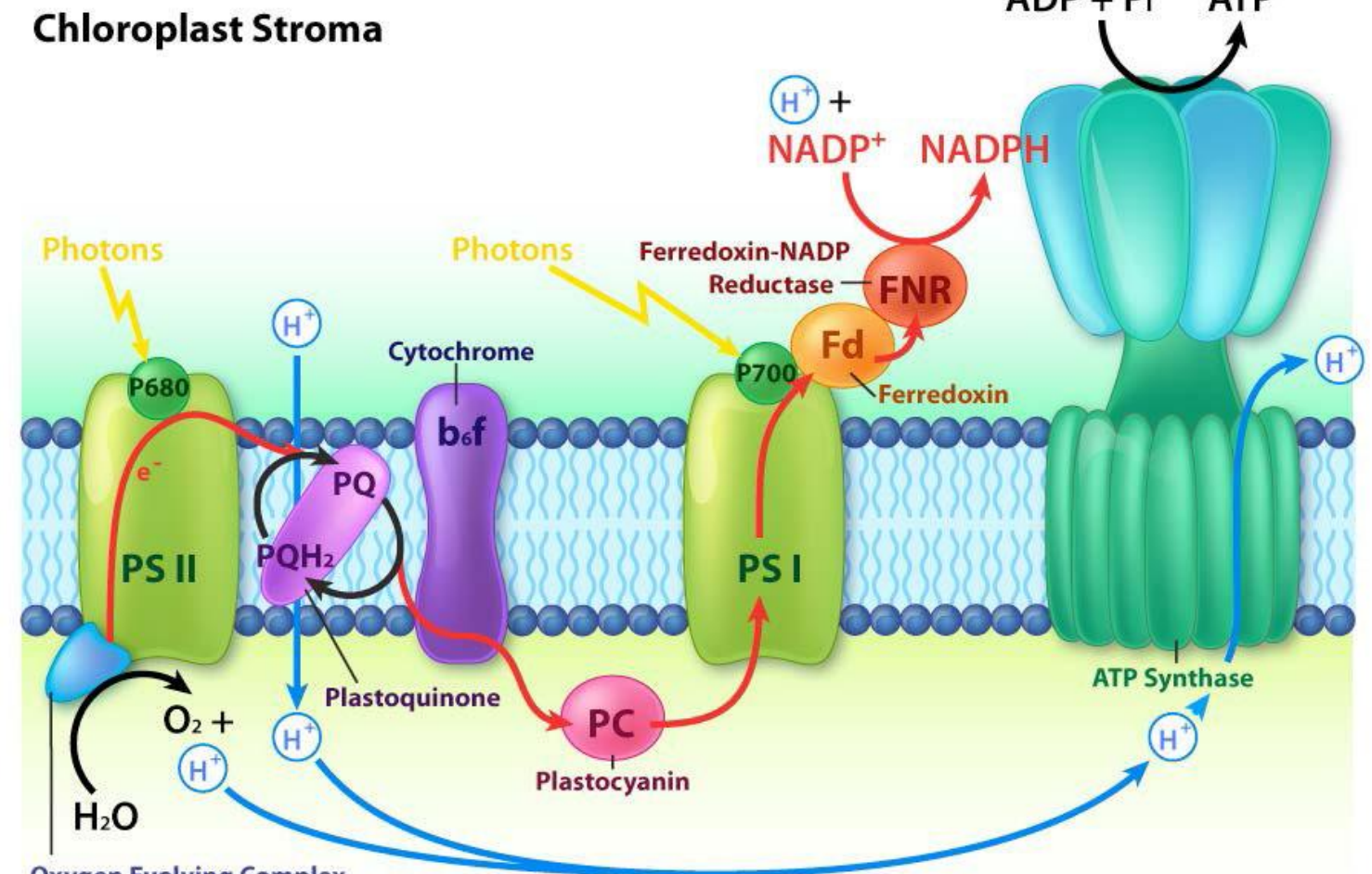

Oxygen Evolving Complex

Thylakoid Lumen

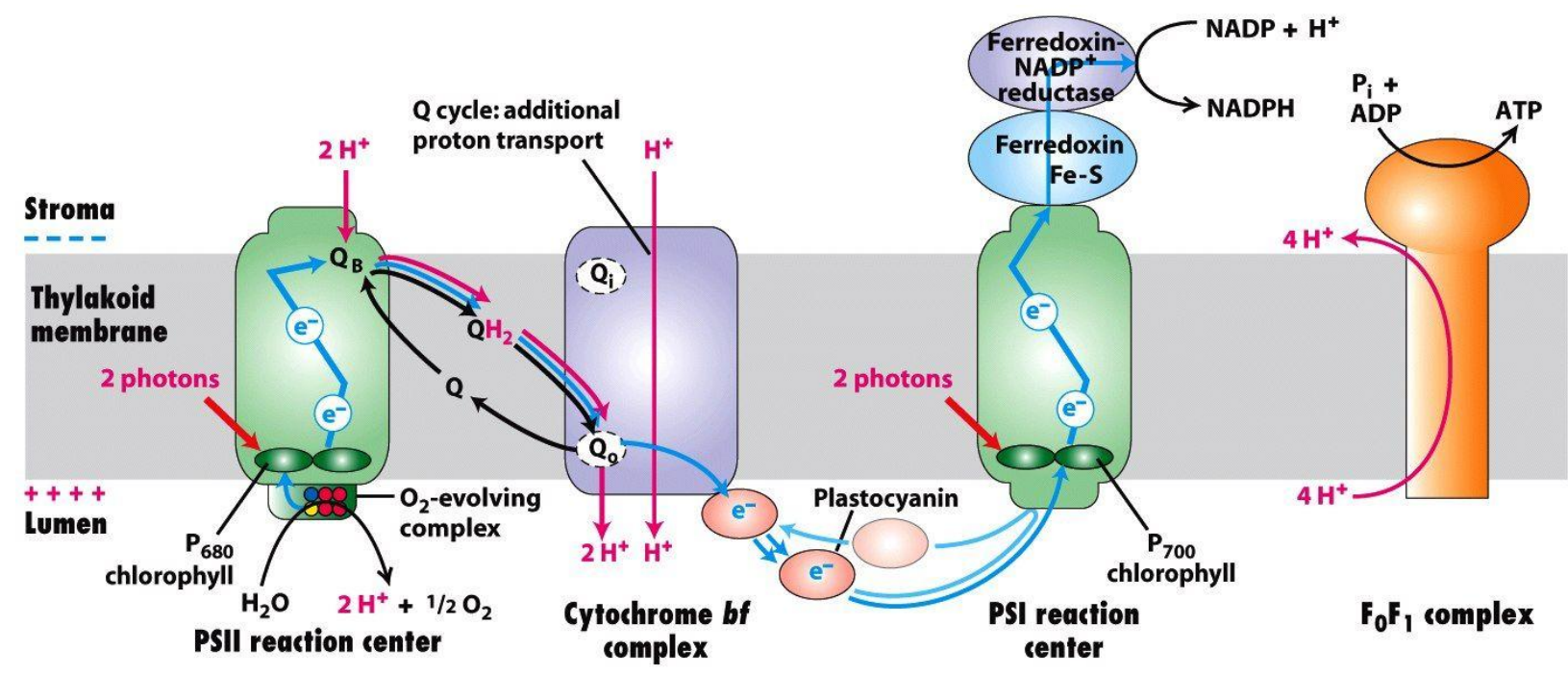

Figure 12-37

Molecular Cell Biology, Sixth Edition

(C) 2008 W. H. Freeman and Company 


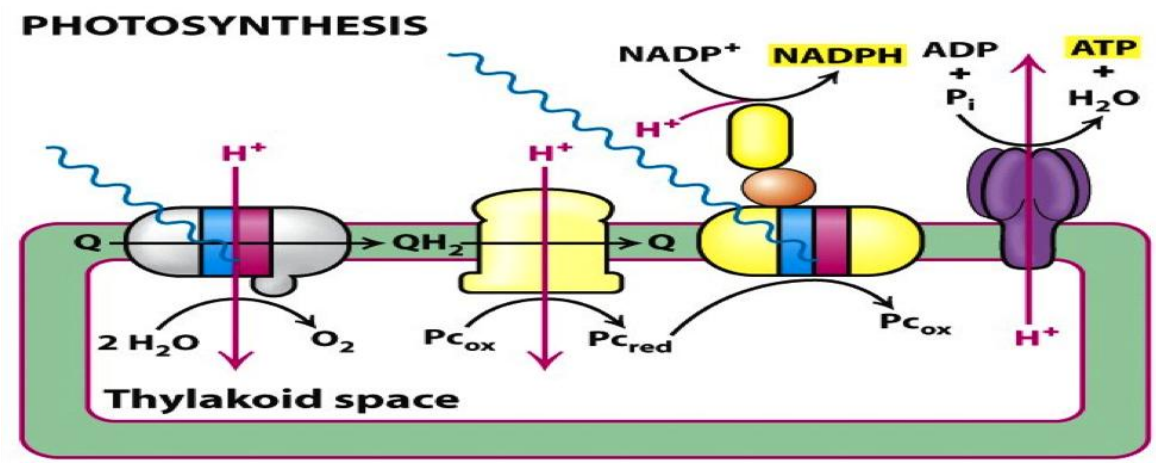

Stroma

OXIDATIVE PHOSPHORYLATION

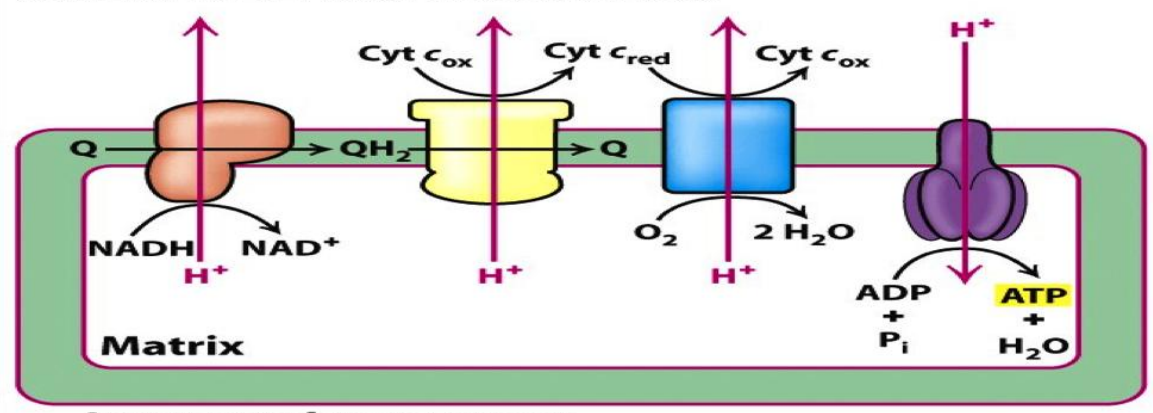

Intermembrane space

Figure 19-25

Biochemistry, Sixth Edition

(6) 2007 W. H. Freeman and Company 